\title{
Decellularization of human dermis using non-denaturing anionic detergent and endonuclease: a review
}

\author{
Mark A. Moore • Brian Samsell • Glenna Wallis • \\ Sherry Triplett · Silvia Chen • Alyce Linthurst Jones • \\ Xiaofei Qin
}

Received: 24 March 2014/ Accepted: 9 August 2014/Published online: 28 August 2014

(C) The Author(s) 2014. This article is published with open access at Springerlink.com

\begin{abstract}
Decellularized human dermis has been used for a number of clinical applications including wound healing, soft tissue reconstruction, and sports medicine procedures. A variety of methods exist to prepare this useful class of biomaterial. Here, we describe a decellularization technology (MatrA$\mathrm{CELL}^{\circledR}$ ) utilizing a non-denaturing anionic detergent, $\mathrm{N}$-Lauroyl sarcosinate, and endonuclease, which was developed to remove potentially immunogenic material while retaining biomechanical properties. Effective decellularization was demonstrated by a residual DNA content of $\leq 4 \mathrm{ng} / \mathrm{mg}$ of wet weight which represented $>97 \%$ DNA removal compared to unprocessed dermis. Two millimeter thick MatrACELL processed human acellular dermal matrix (MH-ADM) exhibited average ultimate tensile load to failure of $635.4 \pm 199.9 \mathrm{~N}$ and average suture retention strength of $134.9 \pm 55.1 \mathrm{~N}$. Using an in vivo mouse skin excisional model, MH-ADM was shown to be biocompatible and capable of supporting cellular and vascular in-growth. Finally, clinical studies of $\mathrm{MH}-$ ADM in variety of applications suggest it can be an appropriate scaffold for wound healing, soft tissue reconstruction, and soft tissue augmentation.
\end{abstract}

M. A. Moore $(\bowtie) \cdot$ B. Samsell · G. Wallis ·

S. Triplett · S. Chen · A. L. Jones · X. Qin Institute of Regenerative Medicine, LifeNet Health, 1864 Concert Drive, Virginia Beach, VA 23453, USA

e-mail: mark_moore@lifenethealth.org
Keywords Allograft · Homograft · Dermis · Decellularized - Acellular dermal matrix . MatrACELL

\section{Introduction}

Decellularization technology has been utilized to remove cellular components in a variety of soft tissues including cardiovascular allograft and human dermal matrix to produce bio-implants for clinical application. The objectives of the decellularization process are to remove potentially immunogenic material and provide a biocompatible scaffold for host cellular and vascular in-growth (Norton and Babensee 2009). Following decellularization, the remaining extracellular matrix can also be used as a scaffold for tissue engineering (Pellegata et al. 2013). Decellularized cardiovascular tissue has been applied in a variety of in vivo applications (Ketchedjian et al. 2005a, b; Hopkins et al. 2009; Elkins et al. 2001a, b; Sievers et al. 2003; Simon et al. 2003; Hawkins et al. 2003; Bechtel et al. 2003, 2005; Kasimir et al. 2006; Steinhoff et al. 2000; Cebotari et al. 2002). Similarly, human acellular dermal matrix (ADM) has been used for wound healing, soft tissue reconstruction, and sports medicine applications. Specifically, human ADM has been reported to be used clinically for repair of rotator cuff tears (Wong et al. 2010; Snyder and Bone 2007; Barber et al. 2008; Burkhead et al. 
2007; Bond et al. 2008; Dopirak et al. 2007), during which the dermal matrix is typically used to augment a repair procedure in order to provide biomechanical strength as well as support directed healing. Also, Achilles and quadriceps tendon augmentation procedures using human ADM are reported with satisfying clinical outcomes (Wilkins 2010; Lee 2007, 2008; Barber et al. 2006). In addition, human ADM is commonly used for soft tissue reconstruction procedures including primary, staged, and revision breast reconstruction (Sbitany et al. 2009; Nahabedian 2009; Salzberg 2006) and hernia repair (Kapfer and Keshen 2006; Albo et al. 2006; Candage et al. 2008; Mitchell and Cima 2011). Moreover, human ADM is widely used in the treatment of chronic wounds such as diabetic foot ulcers (Winters et al. 2008; Randall et al. 2008; Brigido et al. 2004).

In particular, one decellularization technology, Ma$\operatorname{trACELL}^{\circledR}$ (US Patent 6,743,574 (2004)) (LifeNet Health, Virginia Beach, VA), has been applied to human pulmonary patches, which received 510(k) clearance from the FDA and has been in clinical use since 2009 (Lofland et al. 2012). The same MatrACELL technology is also applied to human dermis and the resultant $\mathrm{ADM}$ is referred to here as MatrACELL processed human acellular dermal matrix (MH-ADM). The processing, properties, and potential applications of MH-ADM are reviewed herein.

\section{The MatrACELL decellularization and sterilization process}

The MatrACELL decellularization process was developed to minimize the impact of processing reagents on biomechanical and biochemical properties of the tissue while still removing cellular components (US Patents 6,734,018 (2004); 7,338,757 (2008)). MatrACELL- processed tissue is rendered acellular in a solution of non-denaturing anionic detergent $(\mathrm{N}-$ Lauroyl sarcosinate, NLS), recombinant endonuclease, and antibiotics (including Polymixin B, Vancomycin and Lincomycin). Following decellularization, the tissue is thoroughly rinsed to remove the decellularization reagents. Next, the bio-implant is treated with a water replacing agent, such as glycerol (US Patents 6,293,970 (2001); 6,544,289 (2003); $6,569,200$ (2003); 7,063,726 (2006)), prior to final packaging of the tissue. This allows room temperature storage and rapid preparation by the end user. Finally, the bio-implant is terminally sterilized with low temperature, low dose gamma irradiation (Moore et al. 2004). This final step results in a Sterility Assurance Level (SAL) of $1 \times 10^{-6}$ as anticipated for a medical device, while also inactivating viruses (Moore 2012). The entire process retains biomechanical and biocompatible (Qin et al. 2008) properties of the MH-ADM.

\section{Preclinical evaluation of MH-ADM}

MH-ADM was assessed via analytical methods, biomechanical testing, and in vivo analysis. Representative study results are presented in this review. Results from original data sets are not intended to be generalizable, but add novel information to be considered in totality with the other studies presented here.

\section{Histological analysis overview}

The MH-ADM process is designed to remove cellular remnants from tissue. Evidence of decellularization by histological analysis is demonstrated by the absence of cell nuclei (Fig. 1) and cell membrane components such as major histocompatibility complex I (MHC-I) (Fig. 2). MHC-I plays a vital role in cell immunity, but is considered an undesirable cellular remnant in tissue implantation (Steinmetz 1986). This is due to MHCI's capability of activating recipient's immune response, specifically CD8 $+\mathrm{T}$ cells, against the newly implanted tissue, and, thus, its removal is desirable for clinically implantable materials.

\section{Analysis of DNA residuals}

The DNA content in the MH-ADM was quantified using Quant-iT ${ }^{\mathrm{TM}}$ PicoGreen ${ }^{\circledR}$ dsDNA assay kits (Life Technologies, Inc., Carlsbad, CA) and calculated as $\mathrm{ng} / \mathrm{mg}$ tissue weight (Table 1) using one tissue sample each from three donors $(n=3)$. Compared to unprocessed dermis, at least $97 \%$ of DNA content was removed through processing.

In contrast, the post-processing DNA content of two other commercially available decellularized human tissues, AlloDerm ${ }^{\circledR}$ (LifeCell Corporation, Branchburg, NJ) and GraftJacket ${ }^{\mathrm{TM}}$ (Wright Medical 


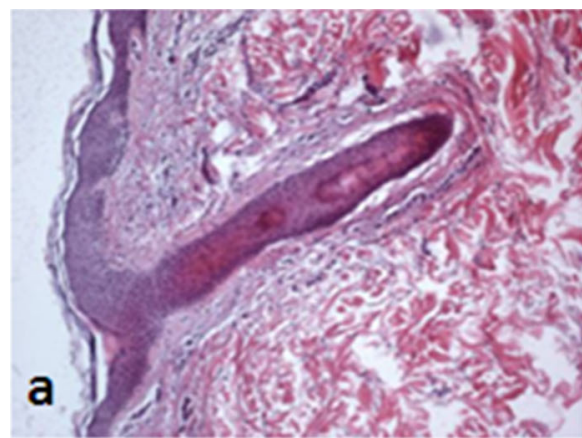

Fig. 1 Histological analysis of human skin tissue. a prior to and b after MatrACELL processing. Hemotoxylin and eosin (H\&E) staining shows nuclear material (blue/purple staining). Note the presence of stained nuclear material prior to decellularization

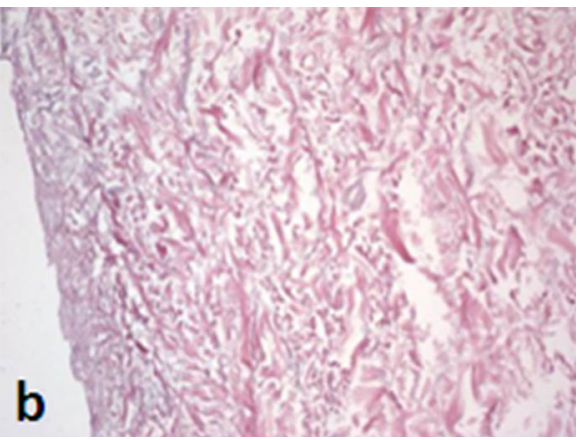

(a) in contrast to the lack of nuclear material in the tissue after the MatrACELL process in MH-ADM (b). (Data on file at LifeNet Health). (Color figure online)

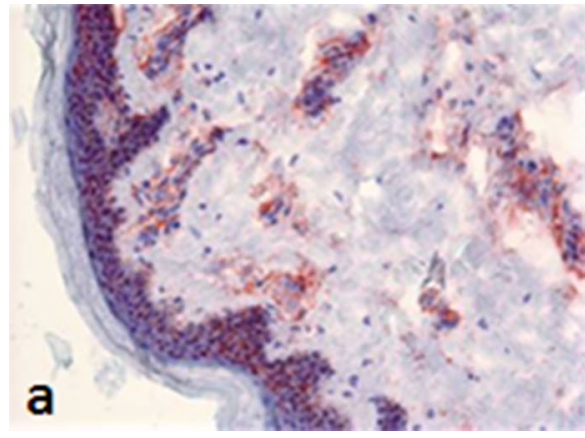

Fig. 2 Major Histocompatibility Complex I (MHC-I) staining of human skin tissue a prior to and $\mathbf{b}$ after the MatrACELL process. MHC-I staining was used to detect cells and cellular remnants. Note the presence of brick-red stained MHC-I

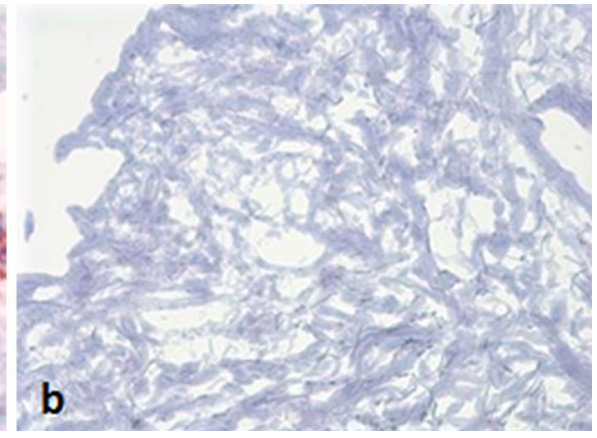

positive cells prior to decellularization (a) in contrast to the absence of MHC-I staining in the tissue after the MatrACELL process (b). (Data on file at LifeNet Health). (Color figure online)

Table 1 DNA content for dermis before and after the MatrACELL decellularization process quantified at minimal, nominal, and maximal processing parameters

\begin{tabular}{llllll}
\hline Condition & $\begin{array}{l}\text { Average DNA in dermis } \\
\text { (ng/mg wet weight) }\end{array}$ & $\begin{array}{l}\text { Avg standard } \\
\text { deviation }\end{array}$ & $\begin{array}{l}\text { Average DNA in MH-ADM } \\
\text { Dermis (ng/mg wet weight) }\end{array}$ & $\begin{array}{l}\text { Avg standard } \\
\text { deviation }\end{array}$ & Reduction (\%) \\
\hline Minimum & 118.18 & 19.23 & 1.67 & 0.16 & 98.58 \\
Nominal & 107.36 & 13.89 & 2.78 & 0.14 & 97.41 \\
Maximum & 132.98 & 12.24 & 1.76 & 0.12 & 98.68 \\
\hline
\end{tabular}

All DNA content results are presented as ng/mg of wet weight of material (Data on File, $\mathrm{n}=3$ as 1 sample each from 3 donors, LifeNet Health). Note the substantial DNA reduction at all parameters as compared to the non-decellularized dermis control. Also note, in contrast to Fig. 3, these values are presented per wet weight of dermis

Technology, Inc., Arlington, TN), as reported in the literature (Derwin et al. 2006; Choe and Bell 2001) were much greater than that found in MH-ADM (Fig. 3). The content of DNA in MH-ADM was measured to be $15.97 \pm 4.8 \mathrm{ng} / \mathrm{mg}$ dry weight. Using a similar PicoGreen dsDNA Assay (Molecular Probes), DNA content in GraftJacket was reported to be an average $134.6 \pm 44.0 \mathrm{ng} / \mathrm{mg}$ dry weight (Derwin et al. 2006) and $272.8 \pm 168.8 \mathrm{ng} / \mathrm{mg}$ tissue for AlloDerm (Choe and Bell 2001). 


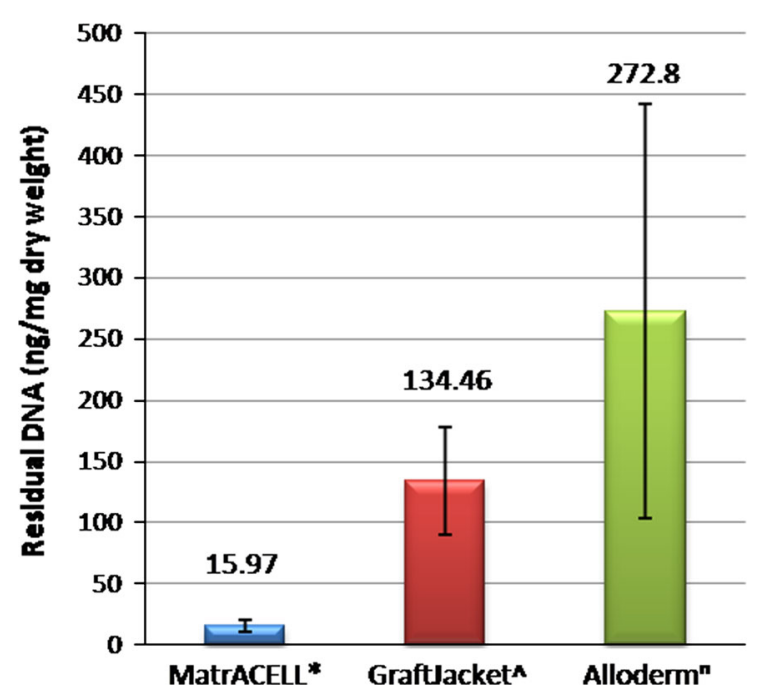

Fig. 3 Comparison of residual DNA content in three ADM. All DNA content results are presented as $\mathrm{ng} / \mathrm{mg}$ of dry weight of material. Please note this is not a side-by-side experiment, rather a comparison to the literature. However, all values are represented as ng/mg dry weight of tissue, and the method of detection was identical. Asterisk MH-ADM (Data on file at LifeNet Health, $\mathrm{n}=3$ as 1 sample each from 3 donors) and values reported in the literature for: ${ }^{\wedge}$ GraftJacket (Derwin et al. 2010), ${ }^{\mathrm{n}}$ AlloDerm (Choe and Bell 2001)

\section{Biomechanical testing overview}

Dependent on the intended use, the biomechanical properties of MH-ADM may be of clinical significance, especially in potentially load bearing applications such as tendon or rotator cuff augmentation. To assess, suture retention strength was measured as the force needed to pull out a 'simple vertical stitch' of Arthrex No.2 FiberWire ${ }^{\circledR}$ (Arthrex, Inc., Naples, FL) passed through the tissue $5 \mathrm{~mm}$ from the edge (Barber and Aziz-Jacob 2009). In addition, ultimate load was determined by pressure clamping two ends of a single layer of material and elongating to failure. The suture retention and ultimate load tests were conducted on two different thicknesses of MH-ADM (2 and $1.5 \mathrm{~mm}$ ) and GraftJacket as well as SportsMesh ${ }^{\mathrm{TM}}$ (Biomet Sports Medicine, LLC, Warsaw, IN) and OrthoDAPT $^{\mathrm{TM}}$ (Pegasus Biologics, Inc., Irvine, CA) (Figs. 4, 5). The mechanical testing focused on different types of soft-tissue augmentation materials and no control was included. Typically, higher suture retention strength and ultimate tensile strength were found in the thicker tissue. While the types of failure for suture pullout were not noted, the ultimate tensile tests primarily failed at the midsection. As demonstrated, the biomechanical integrity of MH-ADM compared favorably with other materials used in soft-tissue augmentation procedures.

Moreover, the biomechanical properties of $\mathrm{MH}$ ADM was investigated (Beitzel et al. 2012) in rotator cuff augmentation procedures performed on randomly assigned cadaveric fresh frozen shoulders. Note that MH-ADM is branded as ArthroFLEX ${ }^{\circledR}$ (Arthrex, Inc., Naples, FL) in this publication. The study compared $\mathrm{MH}-\mathrm{ADM}$ interposed between the bone and tendon as well as placed on top of the repair. Double-row repairs without augmentation served as the control. No significant difference was found in ultimate load to failure between the control group $(348.9 \pm 98.8 \mathrm{~N})$ and the group with interposed MH-ADM $(469.9 \pm 148.6 \mathrm{~N})$. However, the group with $\mathrm{MH}-$ ADM placed on top had significantly higher load to failure $(575.8 \pm 22.6 \mathrm{~N} ; P=0.025)$ than the nonaugmented control $(438.9 \pm 98.8 \mathrm{~N})$.

Additionally, the biomechanical strength of intact scapholunate ligaments and the ligaments reconstructed with 1.5 and $1.0 \mathrm{~mm}$ thick MH-ADM (also described as ArthroFLEX ${ }^{\circledR}$ in this published study by Eshan et al. 2012) was measured in cadaveric tests. While the intact ligament serving as the control failed mid-substance during tensile testing, the $1.0 \mathrm{~mm} \mathrm{MH}$ $\mathrm{ADM}$ reconstructed ligament failed at the suturedermal matrix interface and the $1.5 \mathrm{~mm}$ MH-ADM reconstructed ligament failed at the suture-bone anchor interface. The authors concluded that the positive results warrant further clinical investigation for using MH-ADM as a potential treatment for chronic scapholunate instability.

Small animal study: in vivo results

MH-ADM was tested using a nude mouse skin excisional wound model $(\mathrm{n}=3)$. No control of unprocessed dermis was included as this was intended only as an assessment of processed dermis. In this study, a portion of full thickness skin was excised from the back of a nude mouse and replaced with MH-ADM and covered with a dressing. After 16 days, the implanted dermis was removed and examined histologically for cellularity and inflammation. Normal fibroblast infiltration was observed through the entire thickness of a representative section of implanted dermis (Fig. 6) and the surface of the dermis was re- 


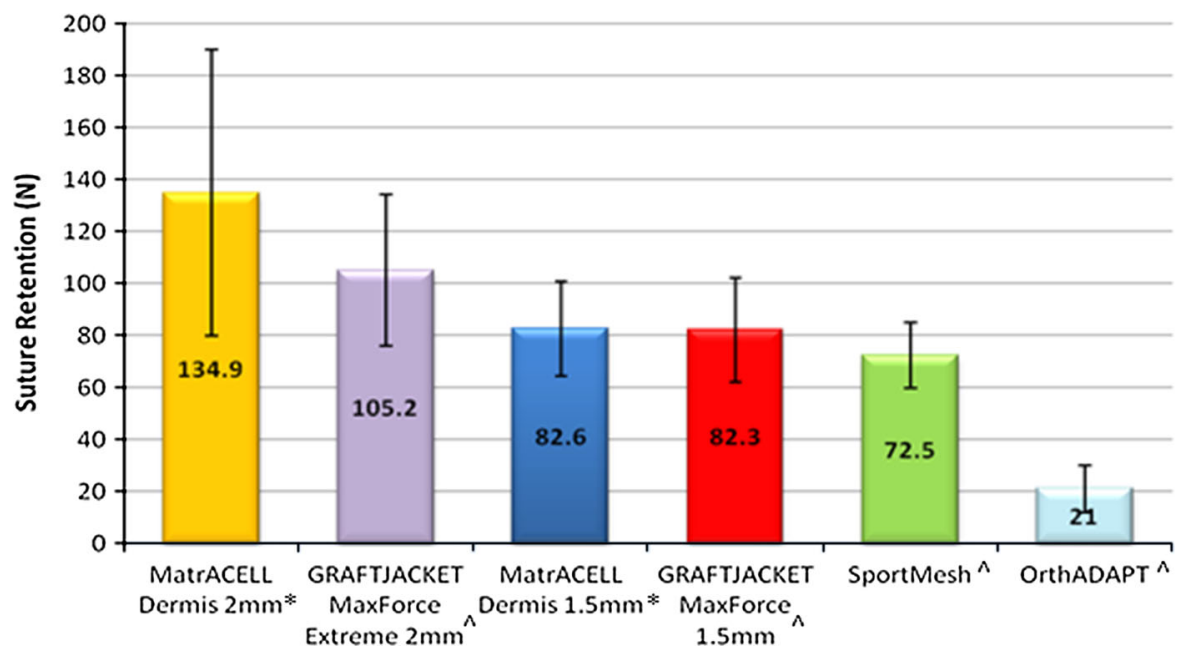

Fig. 4 Suture pullout strength comparison of two thickness MH-ADM (2 mm* and $1.5 \mathrm{~mm} *)$ compared with two thickness GRAFTJACKET and other surgical mesh products $\left({ }^{\wedge}\right)$. Data generated for MatrACELL Dermis and all other materials, respectively was generated at different points in time; however, the exact same methods, fixtures, material testing machine, and facility was used for both studies. Asterisk Data on File at Arthrex (n = 5), ^ Barber and Aziz-Jacobo (2009)

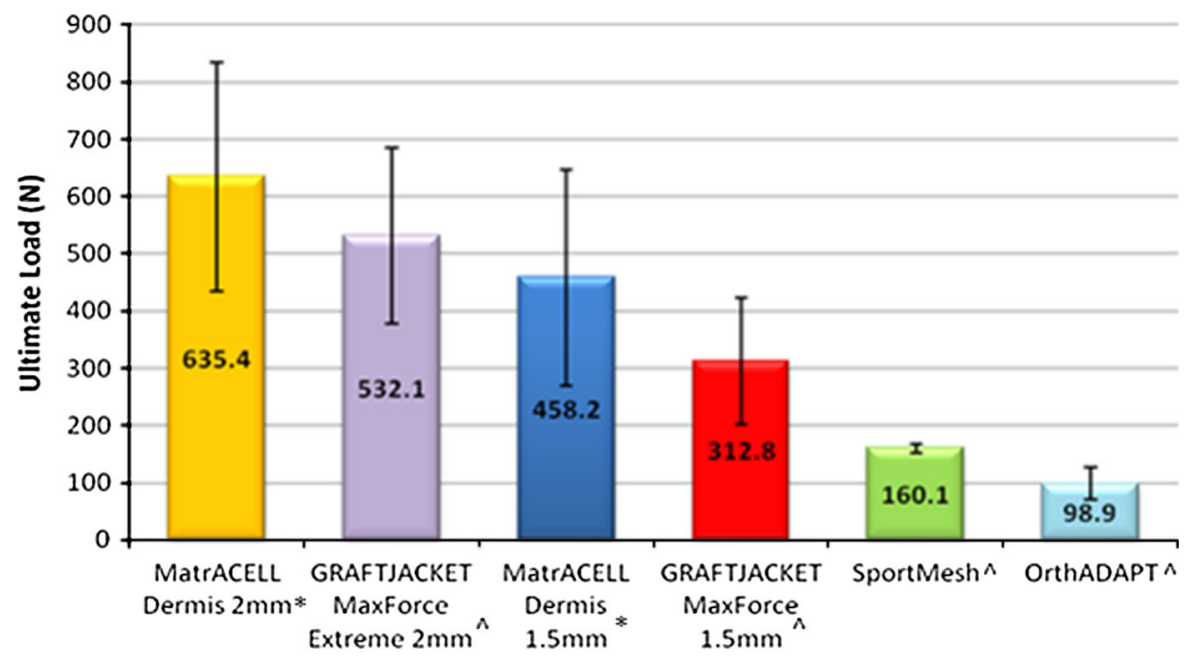

Fig. 5 Ultimate load to failure comparison of two thickness MH-ADM (2 and $1.5 \mathrm{~mm}^{*}$ ) is compared with two thickness GRAFTJACKET and other surgical mesh products $\left({ }^{\wedge}\right)$. Data generated for MatrACELL Dermis and all other materials,

epithelialized partially. Moreover, healthy revascularization was found in the implanted dermis. Minimal inflammatory cells were found in the graft.

Similar results were found for MH-ADM in a study by Capito et al. (2012) where the integrative properties of MH-ADM (also described in the study as DermACELL) and three other ADMs (AlloDerm ${ }^{\mathrm{TM}}$, DermaMatrix $^{\mathrm{TM}}$ (Synthes, Inc., West Chester, PA), and respectively was generated at different points in time; however, the exact same methods, fixtures, material testing machine, and facility was used for both studies. Asterisk Data on File at Arthrex, ^ Barber and Aziz-Jacobo (2009)

Integra $^{\mathrm{TM}}$ (Integra LifeSciences Corporation, Plainsboro, NJ)) were compared in a rat model. Tissue revascularization, recellularization, and integration were evaluated at four time points ranging from 7 to 42 days. Out of the four ADMs evaluated, MH-ADM had the highest cell density measured at 300,600, and $900 \mu \mathrm{m}$ from the blood-vessel graft interface at all time points except Day 42. This difference was 


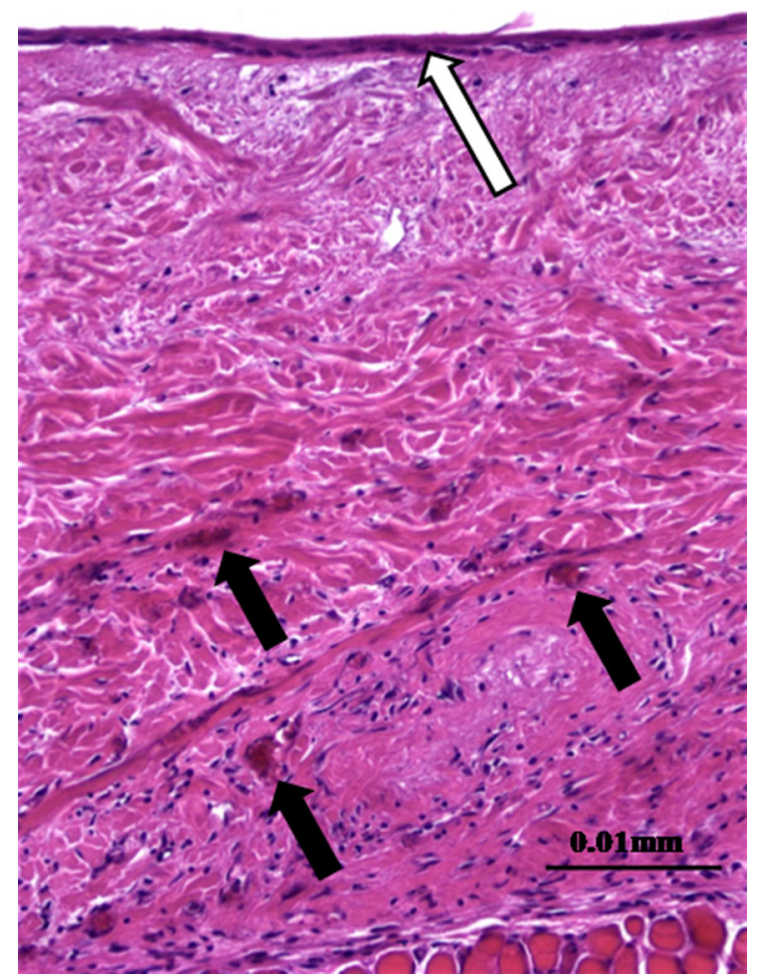

Fig. 6 Hematoxylin and eosin staining of MH-ADM explants using nude mouse skin excisional model. The implant was in place for 16 days prior to excision and analysis. Note the presence of new blood vessels (black arrows) and epithelial layer (open arrow) (data on file at LifeNet Health). (Color figure online)

statistically significant for many of the time points and distances. Furthermore, MH-ADM had the highest amount of cellular infiltration at all time points, which was significantly greater than two of the other ADMs. Additionally, MH-ADM had a statistically significant greater amount of blood vessel formation in the tissue than the other three ADMs at Day 7 and still had a statistically significant greater amount than two other ADMs at Day 42. In all three objective evaluations, MH-ADM compared very favorably with the other three ADMs tested.

\section{Clinical applications of MH-ADM}

Clinical applications of ADMs have been noted in orthopaedic surgeries, dental and craniomaxillofacial repairs, soft tissue reconstruction, and wound healing. Orthopaedic surgeons commonly use ADMs in soft tissue repair procedures to provide additional biomechanical strength and improve healing for rotator cuff repairs, especially for large and massive tears (Wong et al. 2010; Snyder and Bone 2007; Barber et al. 2008; Burkhead et al. 2007; Bond et al. 2008; Dopirak et al. 2007). In addition, ADM was applied to augment Achilles tendon for increased biomechanical strength, possible enhanced healing, and reduced return to activity times (Lee 2007, 2008).

For rotator cuff repair, post-operative reports showed reduced pain and increased motion (Levenda and Sanders 2012). The authors described an arthroscopic technique for performing rotator cuff repair augmented with $\mathrm{MH}-\mathrm{ADM}$ in a 10 patient case series study. At a post operative follow-up of 6 months to 1 year, 9 of 10 patients reported decreased pain and showed increased motion. The 10th patient was also progressing well until a fall, 3 months post-operative, tore the rotator cuff and a total shoulder arthroplasty was performed. The graft augmentation was found to be intact during the arthroplasty. In addition, MHADM was also used in repair and augmentation of Achilles tendon (Fig. 7), quadriceps, and biceps tendon (Fig. 8).

Bone resorption following tooth extraction requires immediate ridge augmentation to prevent further resorption affecting the placement of dental implants (Wallace 2013). MH-ADM was able to facilitate guided bone regeneration (GBR) (Wallace 2013) and soft tissue alveolar ridge augmentation (Al-Hamdan 2011) without the second harvest site morbidity associated with autografts. In another example of dental application (Fig. 9), MH-ADM has been utilized in conjunction with cortical bone particulate to correct for thin bone implant support. After 4 weeks, there was an increase in tissue profile and the gum line had healed smoothly. Additionally, MHADM was used to repair temporal depressions by smoothing over depressions and providing a natural appearance (Fig. 10).

ADMs have been commonly used for treatment of acute and chronic wounds. Non-healing, diabetic ulcers of the lower extremities, particularly the foot, can be treated with an ADM to achieve complete healing and integration while avoiding second site morbidity associated with autografts (Winters et al. 2008; Randall et al. 2008). Yonehiro et al. (2013) successfully treated diabetic foot ulcers using $\mathrm{MH}$ $\mathrm{ADM}$ with a substantial wound healing rate of $83 \%$ in their evaluation of 11 patients with 12 non-healing 

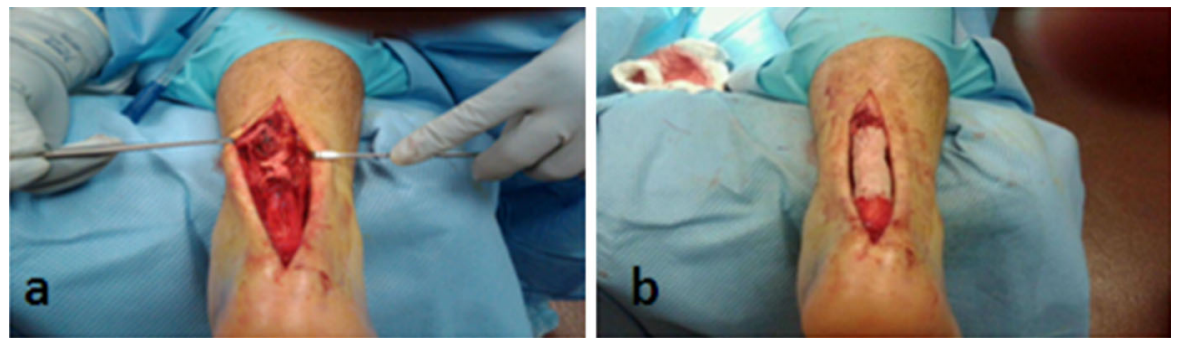

Fig. 7 Use of MH-ADM to augment an Achilles tendon repair. Photo courtesy of Jeffrey Barton, DPM (Delaware Surgery Center, Dover, DE) showed before (a) and after (b) the augmentation

diabetic ulcers. In one of the cases, a 47 year old female presenting with a Wagner Grade 2 non-healing, diabetic ulcer on the plantar first medial head (Fig. 11a) was treated with MH-ADM. The patient went on to a successful outcome with substantial healing at week 12 after a single application of $\mathrm{MH}-$ ADM (Fig. 11b). A burn wound treated using MHADM demonstrated healing, reduced scarring, and

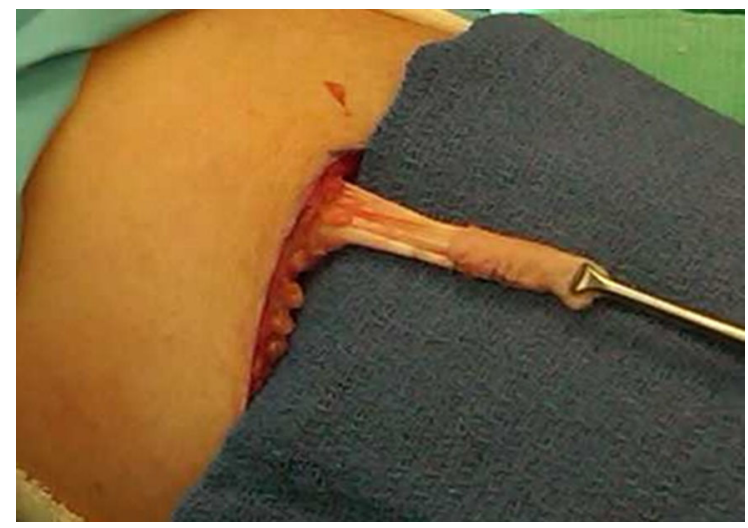

Fig. 8 Use of MH-ADM to augment a biceps tendon repair. Photo courtesy of Raffy Mirzayan, MD, Los Angeles, CA apparent revascularization and recellularization (Chen et al. 2012). In this case study, a patient who suffered from 2nd and 3rd degree burns was initially treated with antibiotics and dressings and over the next 3 years experienced significant scarring and a corresponding restricted range of motion. Following this period, the scar tissue was excised and MH-ADM was applied, and then overlaid with split thickness skin grafts. At 30 days post-operation, the wound bed lacked significant scarring and appeared to have rapid revascularization and recellularization. At 6 months post-operation, the wound healed with significantly less scarring and the patient's range of motion dramatically improved.

Soft tissue reconstruction procedures of the breast and plantar heel also commonly utilize ADMs. Twostage, primary, and revision breast reconstructions used ADM to extend the pectoralis muscle and improve cosmetic appearance while maximizing available skin and reducing reconstruction time (Sbitany et al. 2009; Salzberg 2006; Ortiz 2014). Using MH-ADM, a 46 year old woman underwent a bilateral mastectomy with immediate 2 nd stage breast reconstruction (Fig. 12). Her expanders were filled to
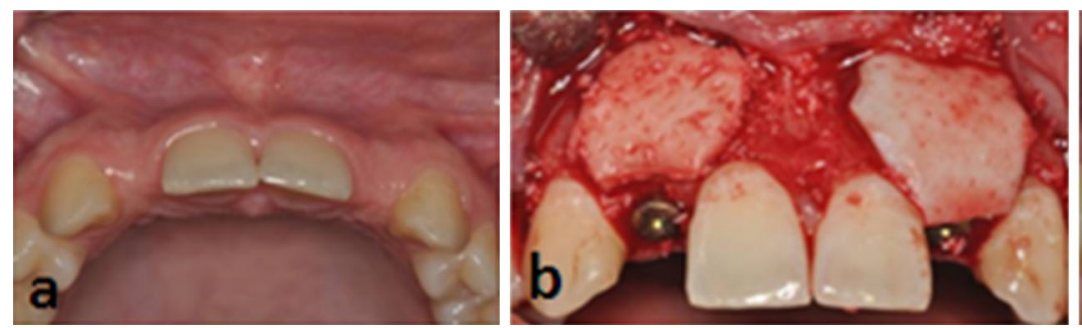

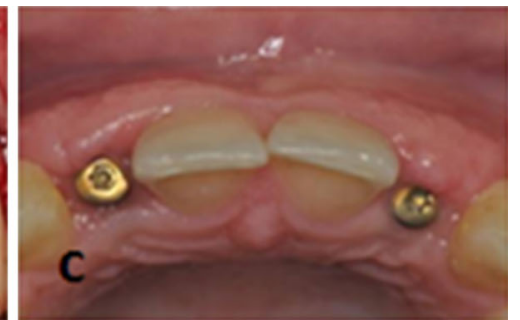

conjunction with implant bone and pins. 4 weeks post-implant demonstrating increase in tissue profile and a smoothly healed gum line. The case photos are courtesy of Paul Rosen, DMD, MS (Yardley, PA)
Fig. 9 Use of MH-ADM in conjunction with cortical bone particulates to correct for the thin bone implant support and to increase the soft tissue profile in these areas. a Pre-surgery showing a thin bone ridge. $\mathbf{b}$ The application of MH-ADM in 

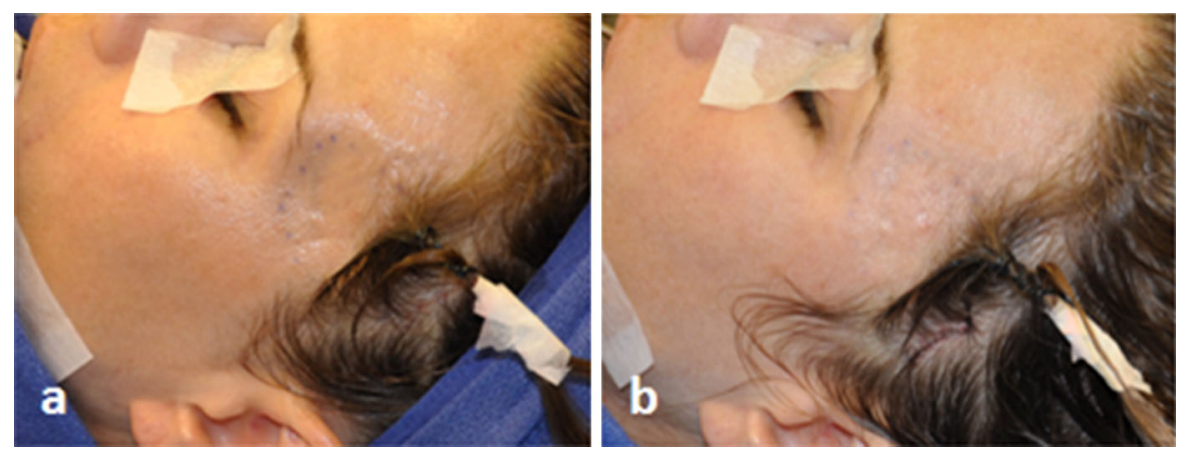

Fig. 10 Use of MH-ADM to repair a temporal depression. a Pre-surgery showing the temporal depression. b The depression smoothing following an incision in the hair line and insertion of MH-ADM. The case photos are courtesy of Barry Eppley, MD (Indianapolis, IN)

$550 \mathrm{cc}$ and after 16 weeks following the mastectomy they were replaced with $700 \mathrm{cc}$ permanent silicone implants. The histological analysis (Fig. 13) on biopsy
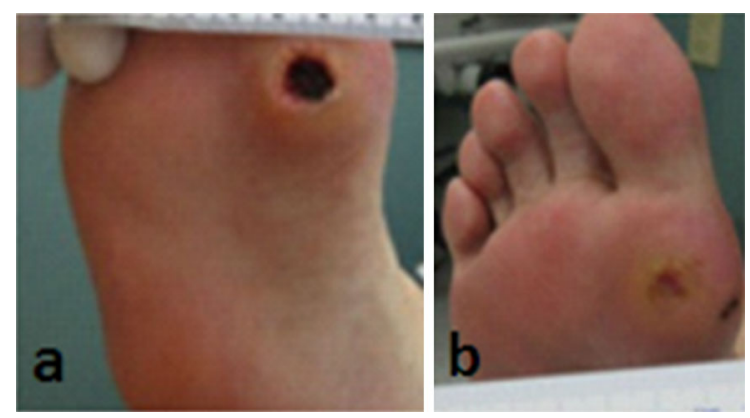

Fig. 11 Use of MH-ADM for wound repair of a diabetic foot ulcer. a 47 y.o. female presented with a Wagner Grade 2 nonhealing diabetic ulcer on the plantar first medial head. b The patient went on to a successful outcome with a single application of MH-ADM as noted by the substantial healing at week 12 (Yonehiro et al. 2013: reproduced with permission of the authors)

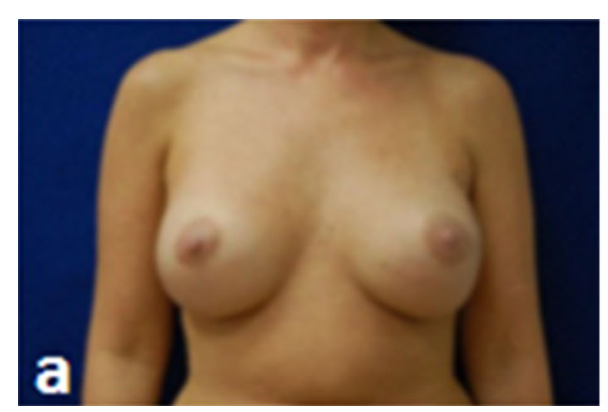

Fig. 12 Use of MH-ADM for breast reconstruction. a preoperative and b post-operative. In this case, a 46 y.o patient received a bilateral mastectomy and advanced to the 2 nd stage tissue demonstrated that the MH-ADM was incorporated into the surrounding tissue. The Hematoxylin and Eosin staining of the biopsy specimen show clearly identifiable intact ultrastructure of extracellular matrix and fibroblast infiltration.

MH-ADM used in tissue replacement of the plantar heel achieved reduced pain involved with ambulation, particularly in weight-bearing areas of the heel (Mulder 2012). In this case series, MH-ADM successfully replaced missing tissue of the plantar heel in 3 patients who had previously lost nearly all of their plantar heel fat pads due to severe motor vehicle accidents. The first patient exhibited encouraging results with pain free ambulation at 6 weeks postoperation and there was continued patient satisfaction at a 3 months post-operative follow-up visit. At over 1 year post-operation, this patient remained pain free. The other two patients did not have long term followups but their initial results were similar to the first patient, supporting the use of MH-ADM for treating plantar defects.

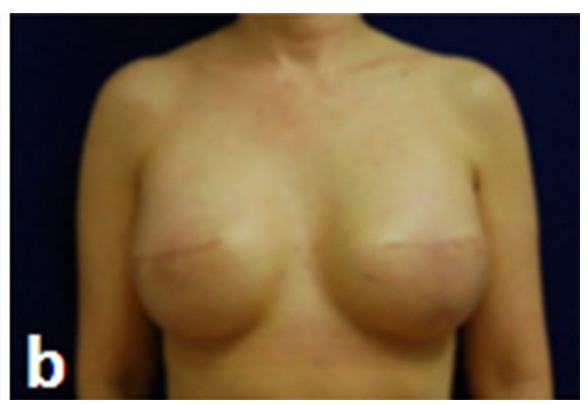

repair. Her expanders were filled to the full $550 \mathrm{cc}$ and replaced with a $700 \mathrm{cc}$ silicone implant 16 weeks following mastectomy (Vashi 2014: reproduced with permission of the author) 


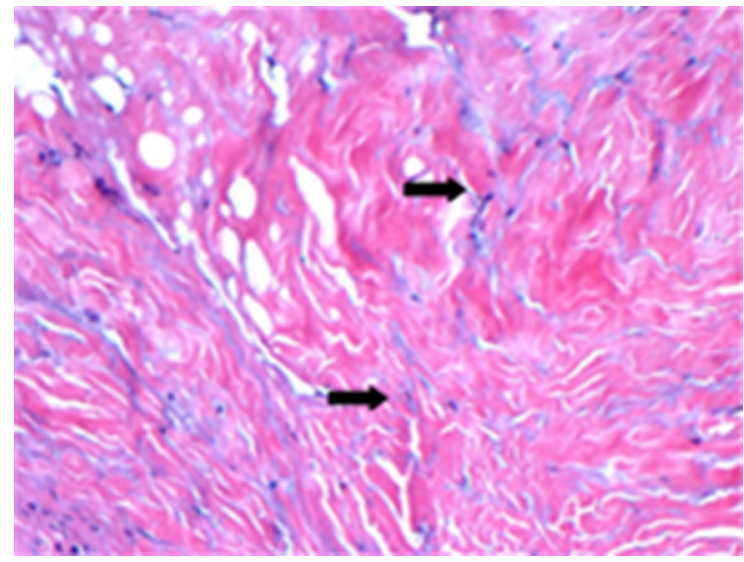

Fig. 13 Hematoxylin and eosin staining of biopsy specimen following 16 weeks in situ placement of MH-ADM in the breast reconstruction surgery shown in Fig. 12. Note the intact ultrastructure and also evidence of cellular in-growth with apparent fibroblasts (arrows) at $10 \times$ magnification (data on file at LifeNet Health). (Color figure online)

\section{Conclusions}

As reviewed here, the MatrACELL process effectively removes cellular material, including DNA and immunogenic components, yielding an acelluar dermis, MH-ADM, which retains biomechanical strength and is biocompatible. Both preclinical and clinical results support the use of this allograft tissue in a myriad of clinical applications, including tendon augmentation, facial reconstruction, wound healing, soft tissue reconstruction, and dental procedures.

Open Access This article is distributed under the terms of the Creative Commons Attribution License which permits any use, distribution, and reproduction in any medium, provided the original author(s) and the source are credited.

\section{References}

Albo D, Awad S, Berger D, Bellows C (2006) Decellularized human cadaveric dermis provides a safe alternative for primary inguinal hernia repair in contaminated surgical fields. Am J Surg 192:e12-e17

Al-Hamdan KS (2011) Esthetic soft tissue ridge augmentation around dental implant: case report. Saudi Dental J 23:205-209

Barber F, Aziz-Jacobo J (2009) Biomechanical testing of commercially available soft-tissue augmentation materials. Arthroscopy 25(11):1233-1239

Barber F, Herbert M, Coons D (2006) Tendon augmentation grafts: biomechanical failure loads and failure patterns. Arthroscopy 22(5):534-538
Barber F, Herbert M, Boothby M (2008) Ultimate tensile failure loads of a human dermal allograft rotator cuff augmentation. Arthroscopy 24:20-24

Bechtel JF, Muller-Steinhardt M, Schmidtke C, Brunswik A, Stierle U, Sievers HH (2003) Evaluation of the decellularized pulmonary valve homograft (SynerGraft). J Heart Valve Dis 12:734-739

Bechtel JF, Gellissen J, Erasmi AW, Peterson M, Hiob A, Stierle U, Sievers HH (2005) Mid-term findings on echocardiography and computed tomography after RVOT-reconstruction: comparison of decellularized (SynerGraft) and conventional allografts. Eur J Cardiothorac Surg 27:410-415

Beitzel K, Chowaniec D, McCarthy MB, Cote M, Russell R, Obopilwe E, Imhoff A, Arciero R, Mazzocca A (2012) Stability of double-row rotator cuff repair is not adversely affected by scaffold interposition between tendon and bone. Am J Sports Med 40(5):1148-1154

Bond JL, Dopirak RM, Higgins J, Burns J, Snyder SJ (2008) Arthroscopic replacement of massive, irreparable rotator cuff tears using a Graft-Jacket allograft: technique and preliminary results. Arthroscopy 24:403-409

Brigido SA, Boc SF, Lopez RC (2004) Effective management of major lower extremity wounds using an acellular regenerative tissue matrix: a pilot study. Orthopedics 27(1):s145-s149

Burkhead WZ, Schiffern SC, Krishnan SG (2007) Use of GraftJacket as an augmentation for massive rotator cuff tears. Semin Arthroplasty 18:11-18

Candage R, Jones K, Luchette F, Sinacore J, Vandevender D, Reed R (2008) Use of human acellular dermal matrix for hernia repair: friend or foe? Surgery 144:703-711

Capito A, Tholpady S, Agrawal H, Drake D, Katz A (2012) Evaluation of host tissue integration, revascularization, and recellularization within various dermal substrates. Ann Plast Surg 68:495-500

Cebotari S, Mertsching H, Kallenbach K, Kostin S, Repin O, Batrinac A, Kleczka C, Ciubotaru A, Haverich A (2002) Construction of autologous human heart valves based on an acellular allograft matrix. Circulation 106:I63-I68

Chen SG, Tzeng YS, Wang CH (2012) Treatment of severe burn with DermACELL ${ }^{\circledR}$, an acellular dermal matrix. Int J Burn Trauma 2(2):105-109

Choe JM, Bell T (2001) Genetic material is present in cadaveric dermis and cadaveric fascia lata. J Urol 166:122-124

Derwin KA, Baker AR, Spragg RK, Leigh DR, Ianotti JP (2006) Biomechanical, biochemical, and cellular properties commercial extracellular matrix scaffolds for rotator cuff tendon repair. J Bone Joint Surg Am 88:2665-2672

Derwin KA, Badylak SF, Steinmann AP, Iannotti JP (2010) Extracellular matrix scaffold devices for rotator cuff repair. J Shoulder Elbow Surg 19:467-476

Dopirak R, Bond JL, Snyder SJ (2007) Arthroscopic total rotator cuff replacement with an acellular human dermal allograft matrix. Int J Shoulder Surg 1:7-15

Elkins RC, Dawson PE, Goldstein S, Walsh SP, Black KS (2001a) Decellularized human valve allografts. Ann Thorac Surg 71:S428-S432

Elkins RC, Goldstein S, Hewitt CW, Walsh SP, Dawson PE, Ollerenshaw JD, Black KS, Clarke DR, O'Brien MF (2001b) Recellularization of heart valve grafts by a process 
of adaptive remodeling. Semin Thorac Cardiovasc Surg 13(4 Suppl 1):87-92

Eshan A, Lee DG, Bakker AJ, Huang JI (2012) Scapholunate ligament reconstruction using an acellular dermal matrix: a mechanical study. J Hand Surg Am 37(8):1538-1542

Hawkins JA, Hillman ND, Lambert LM, Jones J, Di Russo GB, Profaizer T, Fuller TC, Minich LL, Williams RV, Shaddy RE (2003) Immunogenicity of decellularized cryopreserved allografts in pediatric cardia surgery: comparison with standard cryopreserved allografts. J Thorac Cardiovasc Surg 126:247-252

Hopkins RA, Jones AL, Wolfinbarger L, Moore MA, Bert AA, Lofland GK (2009) Decellularization reduces calcification, while improving both durability and one year functional results of pulmonary homograft valves in juvenile sheep. J Thorac Cardiovasc Surg 137:907-913

Kapfer S, Keshen T (2006) The use of human acellular dermis in the operative management of giant omphalocele. J Pediatr Surg 41:216-220

Kasimir MT, Rieder E, Seebacher G, Nigisch A, Dekan B, Wolner E, Wiegel G, Simon P (2006) Decellularization does not eliminate thrombogenicity and inflammatory stimulation in tissue-engineered porcine heart valves. J Heart Valve Dis 15:278-286

Ketchedjian A, Jones AL, Krueger P, Robinson E, Crouch K, Wolfinbarger L Jr, Hopkins R (2005) Recellularization of decellularized allograft scaffolds in ovine great vessel reconstructions. Ann Thorac Surg 79(3):888-896; discussion 896

Ketchedjian A, Krueger P, Lukoff H, Robinson E, Jones A, Crouch K, Wolfinbarger L, Hopkins RA (2005b) Ovine panel reactive antibody assay of HLA responsivity to allograft bioengineered vascular scaffolds. J Thorac Surg 129:155-166

Lee Daniel (2007) Achilles tendon repair with acellular tissue graft augmentation in neglected ruptures. J Foot Ankle Surg 46(6):451-455

Lee Daniel (2008) A preliminary study on the effects of acellular tissue graft augmentation in acute achilles tendon ruptures. J Foot Ankle Surg 47(1):8-12

Levenda A, Sanders N (2012) Arthroscopic technique for augmentation of rotator cuff with a new acellular dermal matrix. Annual meeting of Arthroscopy Association of North America, Orlando, FL

Lofland G, O'Brien J, Gandy K, Dennis P, Marshall J, Mastbergen R, Hopkins R (2012) Initial pediatric cardiac experience with decellularized allograft patches. Ann Thoracic Surg 93:968-971

Mitchell C, Cima R (2011) A novel technique for the repair of urostomal hernias using human acellular dermal matrix. Urology 77(3):746-750

Moore M (2012) Inactivation of enveloped and non-enveloped viruses on seeded human tissues by gamma irradiation. Cell Tissue Bank 13(3):401-407

Moore MA, Jones A, Gaskins B, Wolfinbarger L (2004) Adaptation Of ANSI/AAAMI/ISO 11137 Method 2B sterilization validation for medical devices to tissue banking. American Association of Tissue Banks Annual Meeting, Chicago

Mulder (2012) Tissue augmentation and replacement of a heel fat pad with a decellularized sterile human dermal matrix. Wounds 24(7):185-189
Nahabedian M (2009) AlloDerm performance in the setting of prosthetic breast surgery, infection, and irradiation. Plast Reconstr Surg 124:1743-1753

Norton LW, Babensee JE (2009) Innate and Adaptive Immune Responses in tissue engineering. In: Meyer T, Wiesmann $\mathrm{H}$ (eds) Fundamentals of tissue engineering and regenerative medicine. Springer, Heidelberg, pp 721-745

Ortiz JA (2014) The use of decellularized human dermal allograft for Poland's breast reconstruction. Mil Med 179(2):e249e252

Pellegata AF, Asnaghi MA, Stefani I, Maestroni A, Maestroni S, Dominioni T, Zonta S, Zerbini G, Mantero S (2013) Detergent-enzymatic decellularization of swine blood vessels: insight on mechanical properties for vascular tissue engineering. BioMed Res Int 13:1-8

Qin X, Cotter A, Chen S, Chen J, Wolfinbarger L (2008) Gamma-irradiated human acellular dermis: a potential treatment for wound and soft tissue defects. Society for American Wound Care. 21st Annual Mtg

Randall K, Booth B, Miller A, Russell C, Laughlin R (2008) Use of an acellular regenerative tissue matrix in combination with vacuum-assisted closure therapy for treatment of a diabetic foot wound. J Foot Ankle Surg 47(5):430-433

Salzberg A (2006) Nonexpansive immediate breast reconstruction using human acellular tissue matrix graft (AlloDerm). Ann Plast Surg 57(1):1-5

Sbitany H, Sandeen S, Amalfi A, Davenport M, Langstein H (2009) Acellular dermis-assisted prosthetic breast reconstruction versus complete submuscular coverage: a headto-head comparison of outcomes. Plast Reconstr Surg 124(6): 1735-1740

Sievers HH, Stierle U, Schmidtke C, Bechtel M (2003) Decellularized pulmonary homograft (SynerGraft) for reconstruction of the right ventricular outflow tract: first clinical experience. Z Kardiol 92:53-59

Simon P, Kasimir MT, Seebacher G, Wiegel G, Ullrich R, Salzer-Muhar U, Rieder E, Wolner E (2003) Early failure of the tissue engineered porcine heart valve SYNERGRAFT in pediatric patients. Eur J Cardiothorac Surg 23:1002-1006

Snyder S, Bone J (2007) Technique for arthroscopic replacement of severely damaged rotator cuff using "GraftJacket" allograft. Oper Tech Sports Med 15:86-94

Steinhoff G, Stock U, Karim N, Mertsching H, Timke A, Meliss RR, Pethig K, Haverich A, Bader A (2000) Tissue engineering of pulmonary heart valves on allogenic acellular matrix conduits: in vivo restoration of valve tissue. Circulation 102(19 Suppl 3):50-55

Steinmetz M (1986) The major histocompatibility complex: organization and evolution. Clin Immun News 7(9):134-137

US Patent 6,293,970 (2001) Plasticized bone and soft tissue grafts and methods of making and using same

US Patent 6,544,289 (2003) Plasticized bone grafts, and methods of making and using same

US Patent 6,569,200 (2003) Plasticized soft tissue grafts, and methods of making and using same

US Patent 6,734,018 (2004) Process for decellularizing softtissue engineered medical implants, and decellularized soft-tissue medical implants produced 
US Patent 6,743,574 (2004) Process for devitalizing soft-tissue engineered medical implants, and devitalized soft-tissue medical implants produced

US Patent 7,063,726 (2006) Plasticized bone grafts and methods of making and using same

US Patent 7,338,757 (2008) Process for decellularizing softtissue engineered medical implants, and decellularized soft-tissue medical implants produced

Vashi C (2014) Clinical Outcomes for breast cancer patients undergoing mastectomy and reconstruction with use of DermACELL $^{\circledR}$, a new acellular dermal matrix. Plast Surg Int 2014:1-7

Wallace S (2013) Histomorphometric evaluation of bone regeneration in molar extraction sites using mineralized cancellous allograft and decellularized dermis barrier: a case series. J Oral Implantol 39(4):503-509
Wilkins R (2010) Acellular dermal graft augmentation in quadriceps tendon rupture repair. Curr Orthop Pract 21(3):315-319

Winters C, Brigido S, Liden B, Simmons M, Hartman J, Wright M (2008) A multicenter study involving the use of a human acellular dermal regenerative tissue matrix for the treatment of diabetic lower extremity wounds. Adv Skin Wound Care 21(8):375-381

Wong I, Burns J, Snyder S (2010) Arthroscopic GraftJacket repair of rotator cuff tears. J Shoulder Elbow Surg 19:104-109

Yonehiro L, Burleson G, Sauer V (2013) Use of a new acellular dermal matrix for treatment of non-healing wounds in the lower extremities of the diabetic patient. Wounds 25(12):340-344 